\title{
Patient survival, predictive factors and disease course of severe sepsis in Czech intensive care units: A multicentre, retrospective, observational study
}

\author{
Radovan Uvizla , Milan Adamus ${ }^{\mathrm{a}}$, Vladimir Cerny ${ }^{\mathrm{b}, \mathrm{c}}$, Ladislav Dusek ${ }^{\mathrm{d}}$, Jiri Jarkovsky ${ }^{\mathrm{d}}$, Vladimir Srameke, Martin Matejovic, \\ Petr Stourac ${ }^{\mathrm{d}, \mathrm{g}}$, Roman Kulah, Jan Malaskai, Pavel Sevcik ${ }^{\mathrm{h}, \mathrm{j}}$
}

Background. Severe sepsis/septic shock is associated with high mortality. In Central Europe, there is a dearth of information on the prevalence and treatment of severe sepsis. The EPOSS (Data-based Evaluation and Prediction of Outcome in Severe Sepsis) project launched in 2011 was aimed at collecting data on patients with severe sepsis/septic shock. Methods. The EPOSS study processes data from the EPOSS project database, and is a retrospective, multicentre, observational study. This included all consecutive patients aged 18 and over who were admitted to participating ICUs from 1 January 2011 to 5 November 2013 and met the inclusion criteria of severe sepsis/septic shock. The primary endpoint was to analyse the relationship between in-hospital mortality (either in ICU or after discharge from ICU) and the type and number of fulfilled diagnostic and treatment interventions during the first $6 \mathrm{~h}$ after the diagnosis of severe sepsis/septic shock.

Results. The collected dataset involved 1082 patients meeting the criteria of severe sepsis/septic shock. Following data validation, a final dataset of 897 patients was obtained. The average age of the patient group was 64.7 years; mortality at discharge from EPOSS ICUs was $35.5 \%$ and from hospital $40.7 \%$. Of the 10 evaluated diagnostic and treatment interventions within the initial 6 hours of identifying severe sepsis/septic shock (i.e. fulfilment of SSC bundles), four or five diagnostic and treatment interventions were administered to $58.4 \%$ patients. Combined diagnostic and treatment interventions associated with the lowest in-hospital mortality were: CVP of $\geq 8-12 \mathrm{~mm} \mathrm{Hg} \&$ MAP of $\geq 65 \mathrm{~mm} \mathrm{Hg}$ \& Urine output at $\geq 0.5 \mathrm{~mL} / \mathrm{kg} / \mathrm{h}$ \& Lactate of $\leq 4.0 \mathrm{mmol} / \mathrm{L}$ \& Initial lactate measured \& Antibiotics in the first hour. Lactate at $<4$ $\mathrm{mmol} / \mathrm{L}$ and MAP of $\geq 65 \mathrm{~mm} \mathrm{Hg}$ remained statistically significant even after adjustment for patient age and APACHE II score. Statistically significantly increased in-hospital mortality was found in patients admitted from general departments (45.7\%) or from other ICUs (41.6\%), compared to a lower in-hospital mortality of patients transferred from outpatient clinics (26.5\%) or Emergency (38.0\%). Severe sepsis/septic shock patients transferred from the department of internal medicine were associated with a higher in-hospital mortality (45.1\%) than surgical patients (35.5\%).

Conclusions. The most effective measures associated with the lowest in-hospital mortality in septic shock patients were CVP of $\geq 8-12 \mathrm{~mm} \mathrm{Hg}$, MAP of $\geq 65 \mathrm{~mm} \mathrm{Hg}$, urine output at $\geq 0.5 \mathrm{~mL} / \mathrm{kg} / \mathrm{h}$, initial lactate level of $\leq 4.0 \mathrm{mmol} / \mathrm{L}$ and administration of antibiotics within the first hour.

Key words: severe sepsis, septic shoc, lactate, mortality, assessment

Received: June 20, 2015; Accepted: September 22, 2015; Available online: October 23, 2015

http://dx.doi.org/10.5507/bp.2015.052

${ }^{a}$ Department of Anesthesiology and Intensive Care Medicine, Faculty of Medicine and Dentistry, Palacky University Olomouc and University Hospital Olomouc, Czech Republic

${ }^{b}$ Department of Research and Development, Department of Anaesthesiology and Intensive Care, Faculty of Medicine in Hradec Kralove, Charles University in Prague and University Hospital Hradec Kralove, Czech Republic

'Department of Anaesthesia, Pain Management and Perioperative Medicine, Dalhousie University, Halifax, Canada

${ }^{d}$ Institute of Biostatistics and Analyses, Faculty of Medicine, Masaryk University, Brno, Czech republic

${ }^{e}$ Department Anaesthesia and Intensive Care, Faculty of Medicine, Masaryk University, Brno and St. Anne's University Hospital in Brno, Czech Republic

${ }^{f}$ First Medical Department and Biomedical Centre, Faculty of Medicine in Plzen, Charles University in Prague and Teaching Hospital in Plzen, Czech Republic

${ }^{9}$ Department of Paediatric Anaesthesiology and Intensive Care Medicine, Faculty of Medicine, Masaryk University, Brno and University Hospital Brno, Czech Republic

${ }^{h}$ Department of Anaesthesiology and Intensive Care Medicine, University Hospital Ostrava, Czech Republic

'Department of Anaesthesiology and Intensive Care Medicine, Faculty of Medicine, Masaryk University, Brno and University Hospital Brno,

Czech Republic

'Department of Intensive Care Medicine and Forensic Studies, Faculty of Medicine, University of Ostrava, Czech Republic

Corresponding author: Jan Malaska, e-mail:jmalaska@fnbrno.cz

\section{BACKGROUND}

Sepsis, severe sepsis and particularly septic shock - the most severe form of systemic response to infectious insult
- are all associated with a high mortality rate of $20-70 \%$ depending on patient age, number of failing organ systems and/or comorbidities ${ }^{1-3}$ leaving long-term devastating effects in survivors ${ }^{4}$. A number of national epidemiological 
studies on patients with severe sepsis/septic shock have been described in the literature ${ }^{5-8}$. In the Czech Republic, there is a dearth of publications on both the prevalence and treatment of severe sepsis ${ }^{9}$. The EPOSS (Data-based Evaluation and Prediction of Outcome in Severe Sepsis) project was launched in 2011 with the aim of collecting data on patients with severe sepsis/septic shock and to aid in the evaluation of treatment efficacy ${ }^{10}$. The EPOSS project was conceived as a research project aiming to establish parametric documentation of the treatment of severe sepsis directly in clinical practice and consists of two parts: the EPOSS database (a collaborative programme in which multiple ICUs continuously collect data on severe sepsis) and the EPOSS study (analysis of data gathered in the EPOSS database). This article provides a summary of the results of the EPOSS study. The study assessed compliance with diagnostic and treatment interventions Sepsis Surviving Guidelines during the first 6 hours after the diagnosis of severe sepsis/septic shock. We recorded in-hospital mortality in relation to department from which the patients were transferred to the EPOSS ICU. The study also aimed to identify the most effective combination of diagnostic and treatment interventions related to in-hospital mortality of severe sepsis/septic shock.

\section{METHODS}

According to the STROBE statement ${ }^{11}$.

\section{Setting and study design}

The EPOSS project processes data from the EPOSS project database, and is a retrospective, multicentre, observational study designed to assess both clinical and epidemiological data of ICU patients with severe sepsis in the Czech Republic. The Ethics Committee for Multicentric Trials of the University Hospital in Brno approved the observational study with the need for patient informed consent being waived.

\section{Participants}

All patients aged 18 and over who were consecutively admitted to participating ICUs and met the inclusion criteria of severe sepsis/septic shock as defined by the ACCP/SCCM were included ${ }^{12}$. The condition for patient enrolment was meeting the criteria of severe sepsis/septic shock identified either within the first 24-hour stay in EPOSS-ICUs, or within an interval of $24 \mathrm{~h}$ prior to admission to EPOSS-ICUs, combined with at least one of the criteria of organ dysfunction or clinical or laboratory signs of hypoperfusion according to "Score to assess

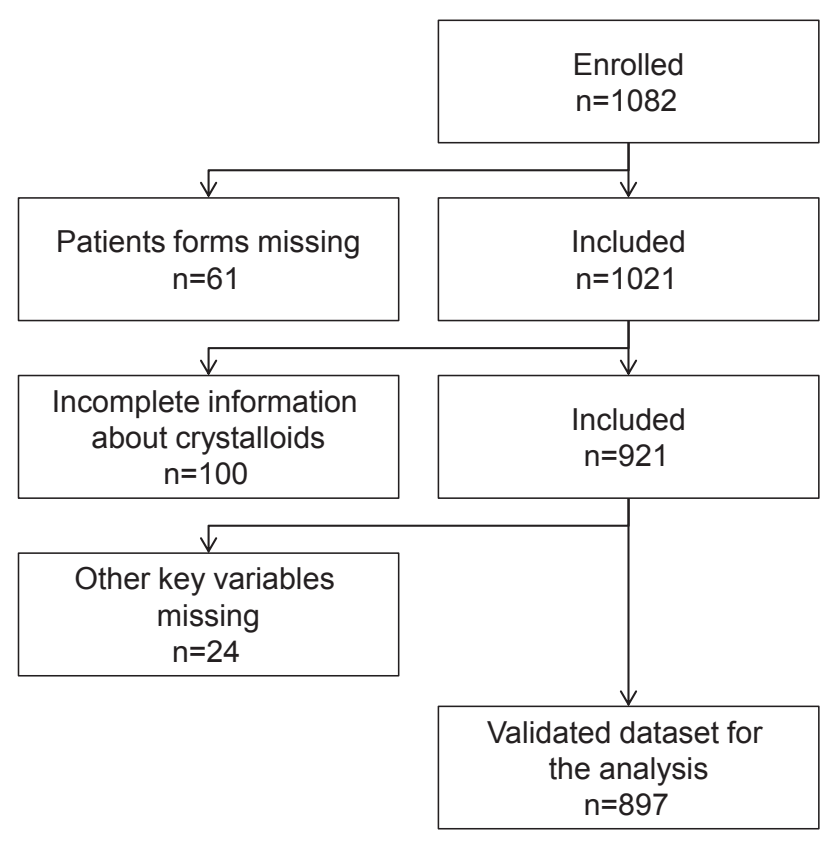

Fig. 1. Flow chart of data validation.

Table 1. Comparison of basic characteristic of patients included and excluded (incomplete data forms) from the analysis.

\begin{tabular}{llccc}
\hline & & \multicolumn{2}{c}{ Patient selection for analysis (n) } & Excluded (185) \\
& & Included (897) & $82(44.3 \%)$ & 0.118 \\
\hline Gender & Female & $342(38.1 \%)$ & $103(55.7 \%)$ & \\
& Male & $555(61.9 \%)$ & $64.0(35 ; 84.0)$ & 0.932 \\
Age at enrollment & median (5-95\% percentile) & $66.0(21.0 ; 92.0)$ & $65(39.4 \%)$ & 0.331 \\
Age category & Up to 60 yrs. & $295(33.0 \%)$ & $48(29.1 \%)$ & $34(20.6 \%)$ \\
& 60-70 yrs & $273(30.5 \%)$ & $18(10.9 \%)$ & \\
& 70-80 yrs. & $193(21.6 \%)$ & $10.0(73.0 ; 17.0)$ & 0.551 \\
SOFA score & More than 80 yrs. & $133(14.9 \%)$ & $28.0(12.0 ; 43.0)$ & 0.055 \\
APACHE II & median (5-95\% percentile) & $10.0(0.0 ; 20.0)$ & $27.3(19.0 ; 46.0)$ & 0.533 \\
BMI (kg/m $\left.{ }^{2}\right)$ & median (5-95\% percentile) & $25.0(2.0 ; 53.0)$ & $11(6.9 \%)$ & 0.315 \\
BMI category & median (5-95\% percentile) & $27.0(11.0 ; 69.1)$ & $51(31.9 \%)$ & \\
& $<=20.0$ & $62(6.9 \%)$ & $43(26.9 \%)$ & $32(20.0 \%)$ \\
& $20.1-25.0$ & $266(29.7 \%)$ & $23(14.4 \%)$ & \\
In-hospital mortality & $314(35.1 \%)$ & $70(37.8 \%)$ & 0.470 \\
\hline
\end{tabular}

Continuous data is described by median and range and tested using Mann Whitney U test. Categorical variables are described by absolute and relative frequencies and tested by ML Chi square test. 
the incidence of organ dysfunction/failure in intensive care units" (SOFA) (ref. ${ }^{13}$ ). Inclusion criteria were always checked on discharge (even for patients who died in the hospital). Patients with incomplete data in their records were excluded (Table 1), (Fig. 1). Appendix 2 shows participating departments [see Additional file - Appendix 2]. The reference period for patient enrolment in the study was from 1 January 2011 to 5 November 2013. The aim of this article is to summarise data for the first one thousand patients in the EPOSS database. Regarding participation in the study, all ICUs in general, teaching and university hospitals in the Czech Republic were invited to cooperate. Participation by individual ICUs was voluntary. Three types of ICU were recorded in the EPOSS project database: surgical, medical and mixed. In the reference period, the following indicators were monitored in participating ICUs: the number of beds, the total number of patients, in-hospital mortality and the average Acute Physiology and Chronic Health Evaluation II (APACHE II) (ref. ${ }^{14}$ ) score of all patients in a given institution within the first $24 \mathrm{~h}$ of admission.

\section{Data management}

The project database was developed and maintained by the Institute of Biostatistics and Analyses, Masaryk University in Brno. Prior to launching the study, representatives of participating centres were trained in entering data into the registry. The project manager communicated electronically with data submitters, and centres involved in the project received a monthly report on the actual number of patients enrolled in the study. Detailed instructions for data entry, as well as the description, professional starting points, organisation and objectives of the project were available to all participants throughout the duration of the study at http://eposs.registry.cz. The Steering Committee continuously coordinated the collection and evaluation of data, and its members were always available to solve any issues.

Patients were monitored until their discharge from the hospital, or until death. Patients' records were used as the data source; data were retrospectively entered in an electronic form and sent to the research database through a web user interface.

The TrialDB application, which was adopted for the EPOSS project, was initially developed by the Centre for
Medical Informatics, Yale University School of Medicine (Connecticut, US), and further amended by the Institute of Biostatistics and Analyses of the Faculty of Medicine and the Faculty of Science of Masaryk University (IBA).

The core of the TrialDB data centre is composed of databases administered in the ORACLE $11 \mathrm{~g}$ system. Such a database is accessed by a web application installed in the application server. The web application is implemented as a package of ASP (Active Server Pages); users may use a current web browser for access, i.e. it is not necessary to install any new software or other accessories. The supported browsers are IE 5.5+, Google Chrome and Mozilla Firefox. Unfortunately, support for rather obsolete browsers is necessary, as they are still broadly used in Czech hospitals.

All the communication between the client application and the server is made via a secured encrypted HTTPS protocol. Only centrally administered and registered users can access the application after entering a correct username and password allocated by the system administrator.

\section{Measurement}

Data were collected during the enrolment of patients into the study. An additional file shows this in more detail [see Additional file - Appendix 3].

Urine output was assessed as a goal of $\geq 0.5 \mathrm{~mL} /$ $\mathrm{kg} / \mathrm{h}$ achieved in the first $6 \mathrm{~h}$, or $\geq 3 \mathrm{~mL} / \mathrm{kg} / 6 \mathrm{~h}$ respectively. Administration of crystalloid bolus $\geq 30 \mathrm{~mL} / \mathrm{kg}$ at MAP $\leq 65 \mathrm{~mm} \mathrm{Hg}$ was assessed collectively over the first 6 hours. Other diagnostic and treatment goals were evaluated after at least $6 \mathrm{~h}$ of treatment.

\section{Outcome Assessment}

The assessed primary endpoint was mortality until discharge from the hospital. We analysed the relationship between in-hospital mortality and the type and number of fulfilled diagnostic and treatment interventions in EPOSS ICUs. An evaluation viewpoint of each diagnostic and treatment intervention was whether it was (or was not) fulfilled within the initial period of six hours after the diagnosis of severe sepsis/septic shock (Table 2). The categories of fulfilled diagnostic and treatment interventions were defined on the basis of their interpretation consistency and adequate sample size. The reference cat-

Table 2. The diagnostic and treatment interventions, assessed within the initial $6 \mathrm{~h}$ of identifying severe sepsis/septic shock.

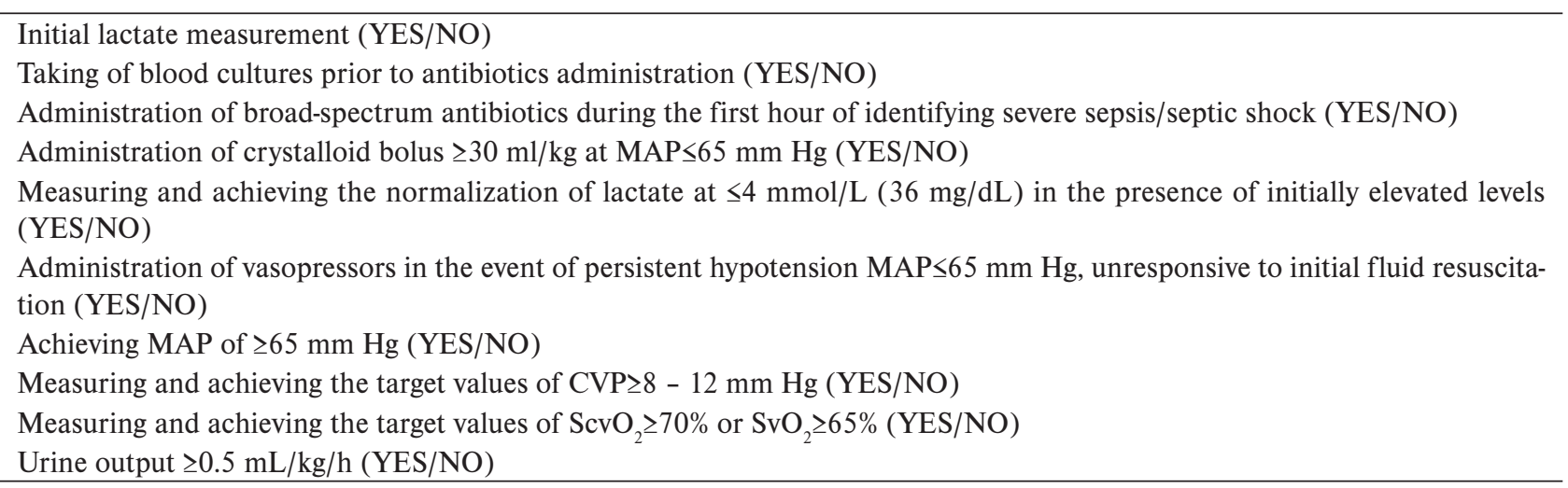


egory with the highest number of fulfilled components was selected as a reference category with the best survival.

We recorded the following basic patient data: gender (male/female), age at enrolment (years), age category (years), SOFA score, APACHE II, BMI $\left(\mathrm{kg} / \mathrm{m}^{2}\right)$, BMI category, in-hospital mortality.

In pursuing the relationship between in-hospital mortality and the admission source to the EPOSS ICU, we evaluated the sources (outpatient clinic, general ward, ER, other ICU), whether the primary admission was medical or surgical, eventually whether surgical admission was elective, acute or traumatological. From the number of completed interventions in the first $6 \mathrm{~h}$, we assessed adherence to the Sepsis Surviving Guidelines.

\section{Definitions}

Sepsis was defined according to the American College of Chest Physicians/Society of Critical Care Medicine (ACCP/SCCM) Consensus Conference ${ }^{12}$.

Infection was defined in accordance with the International Sepsis Forum Consensus Conference on definitions of infection in the intensive care unit ${ }^{15}$.

Severe sepsis/septic shock was defined according to the International Sepsis Forum Consensus Conference on definitions of infection in the intensive care unit ${ }^{16}$.

Organ failure was defined according to a (SOFA) score of $>2\left(\right.$ ref. $\left.^{13}\right)$.

Patients without any reference to trauma or surgery were defined as "medical". "Surgical" patients were those who underwent surgery within four weeks (at the most) prior to the onset of severe sepsis/septic shock. "Planned surgical" were patients who had undergone a planned operation more than $24 \mathrm{~h}$ before the onset of symptoms of severe sepsis/septic shock. "Emergent surgical" were patients with surgery scheduled less than $24 \mathrm{~h}$ before the onset of sepsis symptoms. "Traumatological" were patients admitted in direct relation to trauma or complications relating to a trauma in intervals no more than thirty days before the onset of sepsis. Time 0 was defined in accordance with the International Sepsis Forum Consensus Conference on definitions of infection in the intensive care unit ${ }^{16}$.

"Admission source" was defined as the place from where the patient was directed for admission to EPOSS ICU (outpatient clinic, ER, ward, other ICU).

\section{Statistical Methods}

Patients with incomplete data in key mandatory variables at all time points ( 108 variables) were excluded from the analysis. The time points were: the moment of fulfilling criteria for severe sepsis/septic shock, and moment after the initial $6 \mathrm{~h}$; the sum of variables at these time points (some or all of them depending on a variable) containing data on Age, Gender, APACHE II, SOFA, BMI, Crystalloids, MAP, CVP, Lactate, Antibiotics, Body temperature, Urine output, ScvO2, SvO2, Norepinephrine, Blood culture provides variables in the database. The selection of variables for the multivariate model was based on two principles: i) variables with a $P$ value $<0.1$ in univariate analysis were selected for the development of the multivariate model, ii) redundancy of variables was evaluated and only the most statistically significant variable out of the redundant set of predictors was selected. No replacement of missing values or outliers was performed in order to minimize bias due to changed content of retrospective clinical records. Missing values in mandatory variables were reported in separate tables, and the excluded cases were compared with validated records in order to exclude systematic bias due to data validation. The prerequisites of statistical computations were evaluated using visual inspection of data and normality tests; the redundancy of predictors was evaluated using the analysis of their associations (correlation for continuous variables and contingency table analysis for categorical variables). Standard descriptive statistics were applied to summarize the primary data; continuous variables as means and 95\% confidence intervals or median and range; categorical variables by absolute and relative frequencies. Potential predictors of hospital mortality were analysed using logistic regression and risk or protective association was quantified by odds ratios (OR) with corresponding 95\% confidence intervals. Multivariate logistics regression was adopted for adjusting univariate results for age and APACHE II, and for defining the final multivariate model. The selection of variables for the multivariate model was based on univariate $P<0.1$ and redundancy analysis of these preselected predictors. $P \leq 0.05$ was adopted as the level of statistical significance for all analyses and SPSS 21 (IBM Corporation, 2012) was the software used.

\section{RESULTS}

\section{Participants}

The project was a joint collaboration of 17 ICUs with a total of 220 beds in 12 hospitals. Based on a questionnaire on the long-term global characteristics of these centres, altogether 18,902 patients were admitted during the entire reference period (all diagnoses included). The average patient age was 60.2 years, the average APACHE II score at admission was 20 , and the real in-hospital mortality was $11.4 \%$ irrespective of diagnosis.

\section{Patients}

For the period from 1 January 2011 to 5 November 2013, the EPOSS dataset contained data on 1,082 enrolled patients, and the final validated dataset involved 897 patients. The patient flow is shown in Fig. 1 .

\section{Descriptive data}

The collected dataset included records of 1,082 patients meeting the criteria of severe sepsis/septic shock. Following data validation, a final dataset of 897 patients was obtained. The average patient age of the group was 66.0 years. Table 3 provides more details on the dataset.

\section{Main results and mortality}

All combinations of reported diagnostic and treatment interventions were examined, and the most significant combinations relating to in-hospital mortality were identi- 
Table 3. Basic description at enrolment - gender, age, BMI, SOFA and APACHE II.

\begin{tabular}{lccc}
\hline & Total $(\mathrm{n}=897)$ & \multicolumn{2}{c}{ In-hospital mortality } \\
& & No $(\mathrm{n}=532) 59.3 \%$ & Yes $(\mathrm{n}=365) 40.7 \%$ \\
\hline Female & $342(38.1 \%)$ & $202(38.0 \%)$ & $140(38.4 \%)$ \\
Male & $555(61.9 \%)$ & $330(62.0 \%)$ & $225(61.6 \%)$ \\
Age at enrolment & $66.0(21.0 ; 92.0)$ & $65.0(21.0 ; 92.0)$ & $69.0(21.0 ; 92.0)$ \\
BMI $\left(\mathrm{kg} / \mathrm{m}^{2}\right)$ & $27.0(11.0 ; 69.1)$ & $27.4(11.0 ; 62.3)$ & $26.2(13.1 ; 69.1)$ \\
SOFA score & $10.0(0.0 ; 20.0)$ & $9.0(0.0 ; 20.0)$ & $10.0(1.0 ; 20.0)$ \\
APACHE II & $25.0(2.0 ; 53.0)$ & $23.0(2.0 ; 53.0)$ & $29.0(7.0 ; 51.0)$ \\
\hline
\end{tabular}

Continuous data is described by median and range.

Categorical variables are described by absolute and relative frequencies.

Table 4. Combination of the initial $6 \mathrm{~h}$ fulfilled diagnostic/treatment interventions as factors associated with in-hospital mortality: CVP $\geq 8-12 \mathrm{~mm} \mathrm{Hg}$ (CVP), MAP $\geq 65 \mathrm{~mm} \mathrm{Hg}$ (MAP), Urine output $\geq 0.5 \mathrm{~mL} / \mathrm{kg} / \mathrm{hr}$ (Urine output), Blood culture before ATB therapy (Blood), Lactate $\leq 4.0 \mathrm{mmol} / \mathrm{L}$ (Lactate), Initial lactate measured (Initial lact), Antibiotics in first hour (Antibiotics), $\mathrm{ScvO} 2 \geq 70 \%$ or $\mathrm{SvO} 2 \geq 65 \%(\mathrm{ScvO} 2)$.

\begin{tabular}{|c|c|c|c|}
\hline & $\begin{array}{l}\text { Factor } \\
\text { frequency }\end{array}$ & $\begin{array}{c}\text { In-hospital } \\
\text { mortality }\end{array}$ & $P$ \\
\hline CVP \& MAP \& Urine output \& Lactate \& Initial lact \& Antibiotics & $69(7.7 \%)$ & $23.2 \%$ & 0.003 \\
\hline MAP \& Urine output \& Initial lact \& Antibiotics & $44(4.9 \%)$ & $56.8 \%$ & 0.028 \\
\hline ScvO2 \& MAP \& Urine output \& Blood \& Lactate \& Initial lact & $13(1.4 \%)$ & $15.4 \%$ & 0.082 \\
\hline CVP \& ScvO2 \& MAP \& Urine output \& Lactate \& Initial lact \& Antibiotics & $11(1.2 \%)$ & $18.2 \%$ & 0.147 \\
\hline MAP \& Urine output \& Blood \& Lactate \& Initial lact & $20(2.2 \%)$ & $25.0 \%$ & 0.157 \\
\hline MAP \& Urine output \& Initial lact & $24(2.7 \%)$ & $54.2 \%$ & 0.178 \\
\hline CVP \& MAP \& Urine output \& Lactate \& Initial lact & $20(2.2 \%)$ & $55.0 \%$ & 0.194 \\
\hline
\end{tabular}

Statistical significance is computed for comparison of mortality in the given combination in comparison to the rest of dataset using the maximum likelihood chi-square test

The Table shows the combinations of diagnostic/treatment interventions which achieved a statistical significance or are close to it.

Table 5. Diagnostic/treatment interventions - factor frequency in the initial $6 \mathrm{~h}$, association with in-hospital mortality.

\begin{tabular}{|c|c|c|c|c|}
\hline & $\begin{array}{c}\text { Factor } \\
\text { frequency }\end{array}$ & $\begin{array}{c}\text { In-hospital } \\
\text { mortality }\end{array}$ & $\begin{array}{c}\text { OR } \\
(95 \% \mathrm{CI}) \\
\end{array}$ & $P$ \\
\hline CVP 8 - $12 \mathrm{~mm} \mathrm{Hg}$ & $265(29.5 \%)$ & $37.4 \%$ & $0.83(0.61 ; 1.14)$ & 0.250 \\
\hline $\operatorname{ScvO} 2 \geq 70 \%$ or $\mathrm{SvO} 2 \geq 65 \%$ & $200(22.3 \%)$ & $37.5 \%$ & $1.04(0.55 ; 1.96)$ & 0.898 \\
\hline $\mathrm{MAP} \geq 65 \mathrm{~mm} \mathrm{Hg}$ & $821(91.5 \%)$ & $39.0 \%$ & $0.45(0.28 ; 0.73)$ & 0.001 \\
\hline Urine output $\geq 0.5 \mathrm{~mL} / \mathrm{kg} / \mathrm{h}$ & $668(74.5 \%)$ & $38.3 \%$ & $0.69(0.51 ; 0.93)$ & 0.017 \\
\hline Blood culture before ATB therapy & $220(24.5 \%)$ & $36.4 \%$ & $0.99(0.96 ; 1.03)$ & 0.686 \\
\hline Lactate $\leq 4.0 \mathrm{mmol} / \mathrm{L}$ & $560(62.4 \%)$ & $34.8 \%$ & $0.35(0.25 ; 0.49)$ & $<0.001$ \\
\hline Noradrenaline if MAP $<65 \mathrm{~mm} \mathrm{Hg}$ & $66(88.0 \%)$ & $62.1 \%$ & $3.28(0.75 ; 14.30)$ & 0.114 \\
\hline Crystalloids $\geq 30 \mathrm{~mL} / \mathrm{kg}$ if $\mathrm{MAP}<65 \mathrm{~mm} \mathrm{Hg}$ & $38(50.7 \%)$ & $60.5 \%$ & $1.17(0.47 ; 2.93)$ & 0.740 \\
\hline Initial lactate measured & $746(83.2 \%)$ & $40.8 \%$ & $1.01(0.71 ; 1.45)$ & 0.936 \\
\hline Antibiotics in first hour & $524(58.4 \%)$ & $39.7 \%$ & $0.91(0.69 ; 1.19)$ & 0.472 \\
\hline
\end{tabular}

Odds ratios and their statistical significance derived using univariate logistic regression model.

fied. Only two of these were statistically significant: CVP $\geq 8-12 \mathrm{~mm} \mathrm{Hg} \& \mathrm{MAP} \geq 65 \mathrm{~mm} \mathrm{Hg} \&$ Urine output $\geq 0.5$ $\mathrm{mL} / \mathrm{kg} / \mathrm{hr} \&$ Lactate $\leq 4.0 \mathrm{mmol} / \mathrm{L} \&$ Initial lactate measured \& Antibiotics in first hour $(P=0.003)$ and MAP $\geq$ $65 \mathrm{~mm} \mathrm{Hg} \&$ Urine output $\geq 0.5 \mathrm{~mL} / \mathrm{kg} / \mathrm{hr} \&$ Initial lactate measured \& Antibiotics in first hour $(P=0.028)$, respectively. Table 4 shows the combinations of diagnostic and treatment interventions which were statistically significant or close to it at $P \leq 0.05$.
Diagnostic and treatment interventions related to inhospital mortality which were fulfilled during the first 6 $\mathrm{h}$ and which reached statistical significance were: MAP $\geq$ $65 \mathrm{~mm} \mathrm{Hg}(P=0.001)$, Urine output $\geq 0.5 \mathrm{~mL} / \mathrm{kg} / \mathrm{h}(P=$ $0.017)$ and Lactate $\leq 4.0 \mathrm{mmol} / \mathrm{L}(P<0.001)$, (Table 5).

Assessment of the risk of in-hospital mortality adjusted for age and APACHE II showed that only Lactate $<4$ $\mathrm{mmol} / \mathrm{L}$ and MAP $\geq 65 \mathrm{~mm} \mathrm{Hg}$ were statistically significant $(P<0.001$ for both factors), (Table 6). 


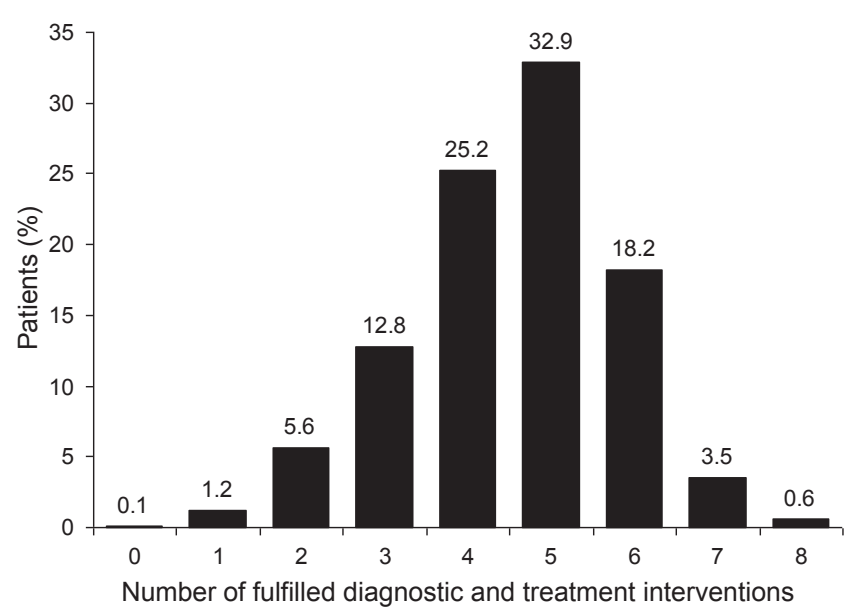

Fig. 2. Number of completed diagnostic and treatment interventions in the initial $6 \mathrm{~h}$.
Of the ten evaluated diagnostic and treatment interventions, $58.1 \%$ of patients fulfilled $4-5$ and $21.7 \%$ of patients achieved 6-7; however, the fulfilment of 8 was only reached in $0.6 \%$ of patients, while joint fulfilment of 9 or all 10 diagnostic and treatment interventions was not achieved in any of the patients (Fig. 2).

In-hospital mortality adjusted for age and APACHE II in relation to admission source to EPOSS ICUs: General wards $(45.7 \%)$, other ICUs $(41.6 \%)$, outpatient (OPD) clinics (26.5\%) and ER (38.0\%) respectively (Table 7).

EPOSS ICU mortality was $35,5 \%$ (women $36.3 \%$, men $35.0 \%$ respectively), mortality at discharge from hospital was $40.7 \%$ (women $40.9 \%$, men $40.2 \%$ respectively).

Variables with $P<0.1$ entered the multivariate analysis of factors associated with in-hospital mortality; all these factors with the exception of urine output $\geq 0.5 \mathrm{~mL} / \mathrm{kg} / \mathrm{h}$ remained statistically significant in the multivariate analysis (Table 8).

Table 6. Risk of in-hospital mortality adjusted to age and APACHE II.

\begin{tabular}{lcc}
\hline & OR & $P$ \\
\hline CVP $8-12 \mathrm{~mm} \mathrm{Hg}$ & $0.88(0.61 ; 1.27)$ & 0.494 \\
$\mathrm{ScvO} 2 \geq 70 \%$ or SvO2 $\geq 65 \%$ & $1.03(0.48 ; 2.22)$ & 0.932 \\
$\mathrm{MAP} \geq 65 \mathrm{~mm} \mathrm{Hg}$ & $0.36(0.20 ; 0.64)$ & $<0.001$ \\
Urine output $\geq 0.5 \mathrm{~mL} / \mathrm{kg} / \mathrm{h}$ & $0.83(0.58 ; 1.19)$ & 0.302 \\
Blood culture before ATB therapy & $0.99(0.95 ; 1.03)$ & 0.665 \\
Lactate $\leq 4.0 \mathrm{mmol} / \mathrm{L}$ & $0.34(0.23 ; 0.50)$ & $<0.001$ \\
Noradrenaline if MAP $<$ 65mm Hg & $2.87(0.42 ; 19.46)$ & 0.280 \\
Crystalloids $\geq 30 \mathrm{~mL} / \mathrm{kg}$ if MAP $65 \mathrm{~mm} \mathrm{Hg}$ & $1.29(0.44 ; 3.78)$ & 0.643 \\
Initial lactate measured & $0.96(0.62 ; 1.50)$ & 0.871 \\
Antibiotics in first hour & $0.92(0.67 ; 1.26)$ & 0.609 \\
Fulfilled 0-3 interventions & $2.16(1.28 ; 3.64)$ & 0.004 \\
Fulfilled 4 interventions & $2.31(1.50 ; 3.54)$ & 0.000 \\
Fulfilled 5 interventions & $1.61(1.10 ; 2.36)$ & 0.015 \\
Fulfilled 6-8 interventions & Reference category of fulfilled components \\
\hline
\end{tabular}

Odds ratios and their statistical significance derived using univariate logistic regression model.

Table 7. Admission source, association with in-hospital mortality (adjusted to age and APACHE II).

\begin{tabular}{llcccc}
\hline & & $\begin{array}{c}\text { Factor } \\
\text { frequency }\end{array}$ & $\begin{array}{c}\text { In-hospital } \\
\text { mortality }\end{array}$ & OR (95\% CI) & $P$ \\
\hline Admission (from) & OPD clinic & $68(7.6 \%)$ & $26.5 \%$ & $0.58(0.30 ; 1.10)$ & 0.094 \\
& General ward & $175(19.5 \%)$ & $45.7 \%$ & $1.41(0.94 ; 2.11)$ & 0.093 \\
& ER & $142(15.8 \%)$ & $38.0 \%$ & $0.81(0.52 ; 1.24)$ & 0.328 \\
& Other ICU & $512(57.1 \%)$ & $41.6 \%$ & $1.05(0.77 ; 1.44)$ & 0.757 \\
Primary admission & Medical & $488(54.4 \%)$ & $45.1 \%$ & $1.54(1.12 ; 2.10)$ & 0.007 \\
& Surgical & $409(45.6 \%)$ & $35.5 \%$ & $0.65(0.48 ; 0.89)$ & 0.007 \\
& Elective (planned) & $107(26.2 \%)$ & $36.4 \%$ & $0.87(0.50 ; 1.52)$ & 0.633 \\
& Acute & $267(65.3 \%)$ & $34.8 \%$ & $0.92(0.55 ; 1.55)$ & 0.762 \\
& Traumatology & $35(8.6 \%)$ & $37.1 \%$ & $2.01(0.78 ; 5.14)$ & 0.147 \\
& Severe sepsis/septic shock & $96(10.7 \%)$ & $42.7 \%$ & $1.12(0.73 ; 1.73)$ & 0.602 \\
& episode in the last 3 months & & & & \\
\hline
\end{tabular}

Odds ratios and their statistical significance derived using univariate logistic regression model. 
Table 8. Multivariate analysis of factors associated with in-hospital mortality.

\begin{tabular}{llcc}
\hline Variables & & OR $(95 \%$ CI $)$ & $P$ \\
\hline Age category & Up to 60 yrs. & Reference & \\
& 60-70 yrs & $1.261(0.803 ; 1.980)$ & 0.315 \\
& $70-80$ yrs. & $1.575(0.966 ; 2.568)$ & 0.068 \\
& More than 80 yrs. & $2.854(1.634 ; 4.984)$ & $<0.001$ \\
Primary admission & Medical & $0.567(0.391 ; 0.823)$ & 0.003 \\
Admission source & OPD clinic & Reference & \\
& General ward & $4.045(1.717 ; 9.530)$ & 0.001 \\
& ER & $1.887(0.791 ; 4.505)$ & 0.153 \\
Apache $>30$ & Other ICU & $2.719(1.233 ; 5.995)$ & 0.013 \\
MAP $\geq 65 \mathrm{~mm} \mathrm{Hg}$ & & $1.810(1.232 ; 2.659)$ & 0.002 \\
Lactate $\leq 4.0 \mathrm{mmol} / \mathrm{L}$ & & $0.405(0.206 ; 0.798)$ & 0.009 \\
Fulfilled interventions & & $0.421(0.267 ; 0.664)$ & $<0.001$ \\
& $0-3$ & $1.688(0.803 ; 3.548)$ & 0.167 \\
& 4 & $1.841(1.082 ; 3.129)$ & 0.024 \\
& 5 & $1.617(1.067 ; 2.452)$ & 0.024 \\
\hline
\end{tabular}

Odds ratios and their statistical significance derived using multivariate logistic regression model.

\section{DISCUSSION}

This is the first-ever study describing the outcome of severe sepsis in ICUs in the Czech Republic. In this way, it provides important information on the epidemiology of severe infections in this country. The main result of the study is identification of combinations of effective diagnostic and treatment interventions within the initial 6 hours of diagnosis/treatment of severe sepsis/septic shock in relation to the lowest in-hospital mortality: CVP $\geq 8-12 \mathrm{~mm} \mathrm{Hg} \&$ MAP $\geq 65 \mathrm{~mm} \mathrm{Hg} \&$ Urine output production $\geq 0.5 \mathrm{~mL} / \mathrm{kg} / \mathrm{h} \&$ Lactate $\leq 4.0 \mathrm{mmol} / \mathrm{L} \&$ Initial lactate measured \& Antibiotics in the first hour. Achieving the key values as MAP $\geq 65 \mathrm{~mm} \mathrm{Hg}$, Lactate $\leq 4.0 \mathrm{mmol} / \mathrm{L}$ and Urine output $\geq 0.5 \mathrm{~mL} / \mathrm{kg} / \mathrm{h}$ in the initial 6 hours of identifying severe sepsis/septic shock is statistically significantly associated with lower than the average in-hospital mortality in the patient group. Given the in-hospital mortality, these values can be assessed as protective. Conversely, persistent hypotension - MAP of $\leq 65 \mathrm{~mm} \mathrm{Hg}$, and the impossibility of achieving this MAP boundary can be assessed as risk factors of in-hospital mortality. Administering a crystalloid bolus of $\geq 30 \mathrm{~mL} /$ $\mathrm{kg}$ at a MAP of $\leq 65 \mathrm{~mm} \mathrm{Hg}$, as well as vasopressors in the case of persistent hypotension, a MAP $\leq 65 \mathrm{~mm} \mathrm{Hg}$, and unresponsive to initial fluid resuscitation, was more prevalent in the deceased than the survivor groups. The result shows that fulfilling important diagnostic and treatment interventions, such as fluid challenge or the support of vasopressors, despite their undeniable therapeutic benefits importance, they did not reduce in-hospital mortality without achieving adequate perfusion pressure. The mere presence of hypotension (MAP $\leq 65 \mathrm{~mm} \mathrm{Hg}$ ) was therefore the major prognostic factor increasing in-hospital mortality. However, the subgroup of patients with hypotension persisting within the initial 6 hours of severe sepsis/septic shock was small $(\mathrm{N}=75)$ and difficult to evaluate statistically.
Arterial blood pressure is a major determinant of regional flow, and is often used as an indicator of tissue perfusion but in reality, it is a poor indicator of blood flow. Distribution of flow for a given blood pressure is dependent on the relative values of the resistance in different vascular beds. Regional resistance cannot be assessed in the clinical setting, and hence we are left with blood pressure as a guide to therapy ${ }^{17}$.

Some authors recommend rethinking resuscitation endpoints in septic shock patients due to potential vasopressor overuse, and suggest tissue hypoperfusion deterioration be used during over emphasis on blood pressure instead of flow. A three-stage approach to resuscitation endpoints has been proposed: Step One (target minimum MAP 45-50 $\mathrm{mmHg}$ to preserve heart and brain perfusion), Step Two (target tissue perfusion-based endpoints irrespective of MAP $<65 \mathrm{mmHg}$ - permissive hypotension), Step Three (target single-organ perfusion) ( ref. $^{18}$ ).

This study found higher in-hospital mortality in patients with severe sepsis/septic shock that developed during hospitalization than in those who were just admitted to hospital with symptoms of severe sepsis/septic shock. The results thus show a higher in-hospital mortality in patients admitted to EPOSS ICUs from general wards (45.7\%) or other ICUs $(41.6 \%)$, in contrast to lower inhospital mortality in patients admitted from outpatient (OPD) clinics $(26.5 \%)$ or ER (38.0\%). This figure suggests a more serious course of sepsis caused more often by multi-resistant strains of hospital-acquired infections in patients already hospitalized, compared to severe sepsis caused in newly hospitalized patients by community infections. In assessing the differences in mortality rates however, we have to consider the potential influence of differences in sepsis-causative organisms, existing comorbidities, and the reason for being hospitalized in the first place. We are aware that although some of these were part of the APACHE II score evaluation, the adjustment might not be complete. 
The results of the EPOSS study are consistent with the conclusions of the pilot study conducted by Malaska et al. ${ }^{10}$. These results showed the different importance of the diagnostic and treatment severe sepsis interventions in relation to in-hospital mortality. In our group of patients, we found a higher in-hospital mortality $(40.7 \%)$ than in the compared studies which, however, do not state the input value of APACHE II (ref. ${ }^{3,19-21}$ ). It is possible that the higher in-hospital mortality we found reflected the severity of patients' conditions (baseline APACHE II in our sample was 25), not only lower fulfilment level for diagnosis and treatment interventions. As expected, we found a statistically significant reduction in in-hospital mortality associated with increase in number of jointly fulfilled diagnostic and treatment interventions. In the group achieving 0-3 diagnostic and treatment interventions, the in-hospital mortality was $47.2 \%$; for 4 and 5 it was $45.3 \%$ and $44.0 \%$ respectively. In the case of jointly fulfilled 6-8 diagnostic and treatment interventions, the in-hospital mortality decreased to $32.5 \%$. The more treatment interventions were achieved within the first $6 \mathrm{~h}$ of treatment, the better was the probability of survival. This finding supports the concept of Sepsis Surviving Guidelines.

Improvements in the outcomes for patients with severe sepsis in relation to fulfilling SSC recommendations were addressed by Castellanos-Ortega et al. These authors reported a significant decrease in mortality within the intervention group compared to the historical group of patients (from $57.3 \%$ to $37.5 \%$ ). An independent predictor of survival was concordance in six and more fulfilled interventions of septic package for the first $6 \mathrm{~h}^{22}$. In the present study, only $22.3 \%$ of our patients fulfilled six or more diagnostic and treatment interventions. This study has made a new contribution with a combination of factors, where reported studies compared only some diagnostic and treatment interventions ${ }^{19,20,22,23}$.

As regards fluids, the current multicentre randomized ProCESS study questioned the importance of EGDT. The study worked with a group of patients with severe sepsis who were initially treated in the ER, i.e. patients newly admitted to hospital, and found no effect of EGDT on inhospital mortality. This was $21.0 \%$ in patients with severe sepsis (EGDT group), 18.2\% (protocol-based standardtherapy group) and $18.9 \%$ (usual-care group) (ref. ${ }^{17}$ ). In our study, cases from the ER formed only $15.8 \%$ of patients (in-hospital mortality 38\%). Recurrence of an episode of severe sepsis/septic shock did not emerge as a significant prognostic factor, as $10.7 \%$ of the patients had already had an attack of severe sepsis/septic shock in the past 3 months. This figure, however, increased the average in-hospital mortality by only $1.4 \%$ to $42.7 \%$. We do not have a clear explanation for this finding. In fact, we expected that an attack of severe sepsis/septic shock in the past three months would lead to a more significant increase in in-hospital mortality.

SSC recommendations between 2008 and 2012 were modified $^{9-11,24}$. Current SSC guidelines do not follow urine output in the initial $6 \mathrm{~h}$. However, we consider the achieved urine output as an important indicator of adequate renal perfusion, together with an adequately conducted fluid strategy; hence its inclusion here.

A major limitation of this study is that the EPOSS database does not provide data categories fully comparable with SSC. For this reason, the comparison of therapeutic interventions with SSC recommendations can only be general. Other limitations are that the study did not include patients with severe sepsis identified after a 24hour stay in EPOSS ICUs or within an interval of more than $24 \mathrm{~h}$ prior to admission to EPOSS ICUs, or patients who had an attack of severe sepsis but were not admitted to any EPOSS ICU. We do not know what proportion of patients with severe sepsis did not pass through EPOSS ICU. The data may also be biased due to the involvement of only large hospitals and only some of their ICUs. We are also aware of the risk of selection bias: it is possible that EPOSS ICUs admitted patients with a poor prognosis where initial treatment in special ICUs or general wards was unsuccessful. The gradual involvement of centres during the observation as well as the absence of a control group is another drawback of our study. We only evaluated a recent group of patients without being able to assess the trend of the results. The strict validation procedure aimed at obtaining fully verified records for analysis, could lead to selection bias; nevertheless, no statistically significant differences in the key characteristics were found between included and excluded patients (Table 8).

Our study, the most extensive in Central Europe, provides extensive data on the epidemiology and observation of treatment parameters in severe sepsis. Until now, the only available results were those of the Slovak study by Zahorec et al. from 2005, which monitored 121 patients with a reported mortality of $51.2 \%\left(\right.$ ref. $\left.^{25}\right)$. The first descriptive data on epidemiology of sepsis/severe sepsis in patients in the Czech Republic was assembled in 2003 thanks to a prospective, multicenter, one-day observational questionnaire by Cerny et al., which included 327 patients from 53 ICUs. Sepsis was diagnosed in 112 patients $(34.2 \%)$ and 55 patients (16.8\%) met the criteria for severe sepsis ${ }^{9}$. In general features, data from the EPOSS study on in-hospital mortality can be compared to data provided by the FINN study from 2007, for example (the ICU and in-hospital mortality in severe septic patients was $15.5 \%$ and $28.3 \%$ respectively) (ref. ${ }^{26}$ ), and more recently, the Intensive Care Over Nations (ICON) audit from 2014 (in-hospital mortality in patients with sepsis was $35.3 \%$ ) $\left(\right.$ ref. $\left.^{27}\right)$. The results of our study showed that efforts in this regard need to focus more intensely on active and early identification of patients with sepsis/severe sepsis and the consistent application of interventions that are based on SSC recommendations. It is necessary to promote the use of early SSC intervention also in patients suspected of developing severe sepsis to preclude mainly the development of hypotension. In relation to in-hospital mortality, we primarily showed the importance of interventions related to adequate organ perfusion. The SSC recommended procedures could be profitably used in patients who only tend to meet the criteria for severe sepsis too, although the 
onset of severe sepsis is already indicated by laboratory evidence of inflammation.

\section{CONCLUSIONS}

The data support the fulfilment of diagnostic and treatment interventions in the early hours after identifying severe sepsis/septic shock. Combined diagnostic and treatment interventions which were fulfilled during the first 6 hours associated with the lowest in-hospital mortality were: CVP of $\geq 8-12 \mathrm{~mm} \mathrm{Hg} \&$ MAP of $\geq 65 \mathrm{~mm} \mathrm{Hg} \&$ Urine output at $\geq 0.5 \mathrm{~mL} / \mathrm{kg} / \mathrm{h} \&$ Lactate of $\leq 4.0 \mathrm{mmol} / \mathrm{L}$ $\&$ Initial lactate measured \& Antibiotics in the first hour. We recorded lower than average in-hospital mortality with Lactate levels of $\leq 4.0 \mathrm{mmol} / \mathrm{L}$ following initial elevation, and a MAP of $\geq 65 \mathrm{~mm} \mathrm{Hg}$. The continuing presence of hypotension at MAP $\leq 65 \mathrm{~mm} \mathrm{Hg}$, even when adequate initial $6 \mathrm{~h}$ fluid resuscitation, was associated with higher than the average in-hospital mortality. Greater in-hospital mortality occurred in patients admitted from general departments or from other ICUs and a lower in-hospital mortality of patients received from outpatient clinics or Emergency. Higher in-hospital mortality in severe sepsis/ septic shock patients was found in patients transferred from the departments of internal medicine than in surgical patients.

\section{ABBREVIATIONS}

ACCP, American College of Clinical Pharmacy; APACHE II, Acute Physiology and Chronic Health Evaluation II; BMI, Body Mass Index; CCTN, the Czech Clinical Trial Network; CSARIM, Czech Society of Anaesthesiology, Resuscitation and Intensive Medicine; CSFS, the Czech-Slovak Forum for Sepsis; CSIM, Czech Society of Intensive Medicine; CVP, Central Venous Pressure; EGDT, Early Goal Directed Therapy; EPOSS, Data-based Evaluation and Prediction of Outcome in Severe Sepsis; ER, Emergency; ICU, Intensive Care Unit; MAP, Middle Arterial Pressure; OPD, Outpatient Department; OR, Odds ratio; SCCM, Society of Critical Care Medicine; ScvO2, Central venous oxygen saturation; SOFA, Score to assess the incidence of organ dysfunction/failure in intensive care units; SSC, Sepsis Surviving Campaign; SvO2, Mixed venous oxygen saturation.

Acknowledgement: The study was conducted under the auspices of the Czech Society of Anaesthesiology, Resuscitation and Intensive Medicine (CSARIM), the Czech Society of Intensive Medicine (CSIM), the CzechSlovak Forum for Sepsis (CSFS) and the Czech Clinical Trial Network (CCTN).

The operation of the project database was supported by an unrestricted research grant from Astra-Zeneca. Author contributions: RU, MA, VC, VS, MM: manuscript writing; MA, VC, VS, MM, LD, JJ, PSt, RK, JM, PSe: study design; RU, MA, VC, LD, JJ, PSe: analysis and in- terpretation of data; MA, VC, MM, VS, PSt, RK: drafting the manuscript and revising it critically for important intellectual content; MA, VC, PSe: agreed to be accountable for all aspects of the work in ensuring that queries relating to the accuracy and integrity of the work are appropriately investigated and resolved; MA, PSe: final approval.

\section{REFERENCES}

1. Vincent J-L, Yasser S, Sprung CHL, Ranieri VM, Reinhart K, Gerlach H, Moreno R, Carlet J, Le Gall JR, Payen D. Sepsis in European intensive care units: Results of the SOAP study. Crit Care Med 2006;34:344-53.

2. Martin GS, Mannino DM, Eaton S, Moss M. The epidemiology of sepsis in the United States from 1979 through 2000. N Engl J Med 2003;348:1546-54.

3. Angus DC, Linde-Zwirbe WT, Lidicker J, Clermont G, Carcillo J, Pinsky MR. Epidemiology of severe sepsis in the United States: Analysis of incidence, outcome, and associated costs of care. Crit Care Med 2001;29:1303-10.

4. Iwashyna TJ, Ely EW, Smith DM, Langa KM. Long-term cognitive impairment and disability among survivors of severe sepsis. JAMA. 2010;304:1787-94.

5. Finfer S, Bellomo R, Lipman J, French C, Dobb G, Myburgh J. Adult population incidence of severe sepsis in Australian and New Zealand intensive care units. Intensive Care Med 2004;30:589-96.

6. Brun-Buisson C, Meshaka P, Pinton P, Vallet B. EPISEPSIS: A reappraisal of the epidemiology and outcome of severe sepsis in French intensive care units. Intensive Care Med 2004;30:580-8.

7. Padkin A, Goldfrad C, Brady AR, Young D, Black N, Rowan K. Epidemiology of severe sepsis occurring in the first $24 \mathrm{hrs}$ in intensive care units in England, Wales, and Northern Ireland. Crit Care Med 2003;31:2332-8.

8. Varpula M, Karlsson S, Parviainen I, Ruokonen E, Pettila V. Community-acquired septic shock: Early management and outcome in a nationwide study in Finland. Acta Anaesthesiol Scand 2007;51:1320-6.

9. Cerny V, Novak I, Sramek V. Prevalence of severe sepsis in the Czech republic-prospective, multicentric, one-day study. Anest. intenziv. Med. 2003;5:218-22.

10. Malaska J, Slezak M, Schwarz D, Jarkovsky J, Adamus M, Cvachovec K, Cerny V, Dostal P, Fortova M, Havel E, Herold I, Kasal E, Kula R, Manak J, Matejovic M, Nalos D, Parizkova R, Sobanova A, Sramek V, Turek R, Zykova I, Dusek L, Sevcik P, Agalarev V, Bakalik P, Belanova V, Cerman J, Ciz L, Dadak L, Duba J, Fortunato J, Gabrhelik T, Gal R, Hulek R, Hrdy O, Huchy M, Chytra I, Klimes D, Klucka J, Kratochvil M, Koskova L, Maca J, Maslik O, Matysova M, Minarcikova P, Molnarova J, Ondraskova H, Pelichovska M, Polak J, Schwarz R, Stasek J, Strazevska E, Suchomelova H, Suk P, Stourac P, Tichy J, Wolfova M, Uvizl R, Zapletalova H, Zatloukal J, Zimova I. Serious sepsis treatment in intensive care departments in the Czech Republic - EPOSS Project pilot results. Vnitr Lek 2013;59: 962- 70.

11. von Elm E, Altman DG, Egger M, Pocock SJ, Gøtzsche PC, Vandenbroucke JP. STROBE Initiative. Strengthening the Reporting of Observational Studies in Epidemiology (STROBE) statement: guidelines for reporting observational studies. J Clin Epidemiol 2008;61(4):344-9.

12. Bone RC, Sibbald WJ, Sprung Cl. The ACCP-SCCM consensus conference on sepsis and organ failure. Chest 1992;101(6):1481-6.

13. Vincent JL, de Mendoca A, Cantraine F, Moreno R, Takala J, Suter PM, Sprung CL, Colardyn F. Use of the SOFA score to assess the incidence of organ dysfunction/failure in intensive care units: Results of a multicentric, prospective study. Crit Care Med 1998;26:1793-1800.

14. Knaus WA, Draper EA, Wagner DP, Zimmerman JE. APACHE II: severity of disease classification system. Crit Care Med 1985;13:818-29.

15. Calandra T, Cohen J. The international sepsis forum consensus conference on definitions of infection in the intensive care unit. Crit Care Med 2005;33: 1538-48

16. Levy MM, Fink MP, Marshall JC, Abraham E, Angus D, Cook D, Cohen J, Opal SM, Vincent JL, Ramsay G. 2001 SCCM/ESICM/ACCP/ATS/SIS International Sepsis Definitions Conference. Intensive Care Med 2003;29: 530-8. 
17. Magder SA. The highs and lows of blood pressure: toward meaningful clinical targets in patients with shock. Crit Care Med 2014;42(5):1241-51

18. Dünser MW, Takala J, Brunauer A, Bakker J. Re-thinking resuscitation: leaving blood pressure cosmetics behind and moving forward to permissive hypotension and a tissue perfusion-based approach. Crit Care 2013;17:326.

19. Yealy DM, Kellum JA, Huang DT, Barnato AE, Weissfeld LA, Pike $F$ Terndrup T, Wang HE, Hou PC, LoVecchio F, Filbin MR, Shapiro NI, Angus DC. A Randomized Trial of Protocol-Based Care for Early Septic Shock. N Engl J Med 2014, DOI:10.1056/NEJMoal1401602

20. Rivers E, Nguyen B, Havstad S, Ressler J, Muzzin A, Knoblich B, Peterson $\mathrm{E}$, Tomlanovich M. Early goal-directed therapy in the treatment of severe sepsis and septic shock. N Engl J Med 2001;345:136877.

21. O Neill R, Morales J, Jule M. Early goal-directed therapy (EGDT) for severe sepsis/septic shock: with components of treatment are more difficult to implement in a community-based emergency department? J Emerg Med 2012;42:503-10.

22. Castellanos-Ortega A, Suberviola B, García-Astudillo LA, Holanda MS, Ortiz F, Llorca J. Impact of the Surviving Sepsis Campaign protocols on hospital length of stay and mortality in septic shock patients: results of a three-year follow-up quasi-experimental study. Crit Care med 2010;38:1036-43.

23. Focht $A$, Jones $A E$, Lowe TJ. Early goal-directed therapy: improving mortality and morbidity of sepsis in the emergency department. Jt Comm J Qual Patient Saf. 2009;35:186-91.

24. Dellinger RP, Levy MM, Rhodes A, Annane D, Gerlach H, Opal SM. Surviving Sepsis Campaign: International guidelines for management of severe sepsis shock: 2012. Crit Care Med 2013;41:580-637.

25. Zahorec R, Firment J, Strakova J, Mikula J, Malík P, Novák I, Zeman $\mathrm{J}$, Chlebo P. Epidemiology of severe sepsis in intensive care units in the Slovak Republic. Infection 2005;33:122-8.

26. Karlsson S, Varpula M, Ruokonen E, Pettila V, Parviainen I, Ala-Kokko $\mathrm{TI}$, Kolho E, Rintala EM. Incidence, treatment, and outcome of severe sepsis in ICU-treated adults in Finland: the Finnsepsis study. Intensive Care Med, 2007;33:435-43

27. Vincent JL, Marshall JC, Namendys-Silva SA, Anzueto A, Martin CD, Moreno R, Lipman J, Gomersall C, Sakr Y, Reinhart K, EPIC II Group of Investigators. Assessment of the worldwide burden of critical illness: the Intensive Care Over Nations (ICON) audit. Lancet Respir Med. 2014 May;2(5):380-6.

\section{APPENDIX 1}

Working group:

V. Agalarev, P. Bakalik, M. Balik, V. Belanova, L. Blahut,

J. Cerman, L. Ciz, K. Cvachovec, L. Dadak, P. Dostal,

J. Duba, M. Fortova, J. Fortunato, T. Gabrhelik, R. Gal,

E. Havel, I. Herold, R. Hulek, O. Hrdy, M. Huchy, I.

Chytra, T. Karvunidis, E. Kasal, D. Klimes, J. Klucka,

M. Kratochvil, L. Koskova, J. Maca, J. Manak, O. Maslik,

M. Matysova, P. Minarcikova, J. Molnarova, D. Nalos, H.

Ondraskova, R. Parizkova, M. Pelichovska, M. Pisar, J.

Polak, D. Schwarz, R. Schwarz, M. Slezak, A. Sobanova,

J. Stasek, E. Strazevska, H. Harazim, P. Suk, J. Tichy,

R. Turek, M. Wolfova, H. Zapletalova, J. Zatloukal, I. Zykova, I. Zimova.

\section{APPENDIX 2}

Centre Participants:

- Department of Anesthesiology and Intensive Care Medicine, Faculty of Medicine and Dentistry, Palacky University Olomouc and University Hospital Olomouc, Olomouc, Czech Republic

- Department of Anaesthesiology and Intensive Care Medicine, University Hospital Ostrava and Faculty of Medicine, University of Ostrava, Czech Republic

- Department of Anaesthesiology and Intensive Care Medicine, University Hospital Praha Motol, Praha, Czech Republic

- Department of Anaesthesia and Intensive Care, St. Anne's University Hospital Brno and Faculty of Medicine, Masaryk University Brno, Czech Republic - Department of Anaesthesiology and Intensive Care Medicine, Faculty of Medicine, Masaryk University Brno and University Hospital Brno, Brno, Czech Republic

- Department of Anaesthesiology and Intensive Care Medicine, Hospital in Zlin, Zlin, Czech Republic

- First Medical Department and Biomedical Centre, Faculty of Medicine in Plzen, Charles University in Prague and Teaching Hospital in Plzen, Czech Republic

- Department of Anaesthesiology and Intensive Care Medicine, Hospital in Liberec, Liberec, Czech Republic

- Department of Anaesthesiology and Intensive Care, Faculty of Medicine in Hradec Kralove, Charles University in Prague and University Hospital Hradec Kralove, Hradec Kralove, Czech Republic

- Department of Anaesthesiology and Intensive Care Medicine, Hospital in Usti nad Labem, Usti nad Labem, Czech Republic

- Department of Anaesthesiology and Intensive Care Medicine, Faculty of Medicine in Plzen, Charles University in Prague and Teaching Hospital in Plzen, Czech Republic

- Department of Anaesthesiology and Intensive Care Medicine, Hospital in Pardubice, Pardubice, Czech Republic

- Medical Department IPVZ, Hospital in Zlin, Zlin, Czech Republic

- Department of Anesthesiology and Intensive Care Medicine, Hospital in Mlada Boleslav, Mlada Boleslav, Czech Republic

- Department of Intensive Care Surgery, Faculty of Medicine and Dentistry, Palacky University Olomouc and University Hospital Olomouc, Olomouc, Czech Republic

- Department of Gerontology and Metabolic Care, Faculty of Medicine in Hradec Kralove, Charles University in Prague and University Hospital Hradec Kralove, Hradec Kralove, Czech Republic

- Department of Anaesthesiology and Intensive Care Medicine, General University Hospital in Praha, Praha, Czech Republic 


\section{APPENDIX 3}

When including patients, the following data was registered:

- Age (years)

- Gender (male/female)

- Admission source to EPOSS-ICU (general ward, other ICUs, ER, outpatient clinic)

- Moment of meeting the criteria of severe sepsis

- APACHE II

In forms, at time of 0,6 hours since identifying severe sepsis, the following data was registered:

- Fluid balance ( $\mathrm{mL} /$ period of time)

- Administered solutions ( $\mathrm{mL} /$ period of time), divided into crystalloids, colloids, albumin, plasma and erythrocyte preparations

- Body temperature $\left({ }^{\circ} \mathrm{C}\right.$ within the period of time $)$
- Administration of vasopressors (type and dose in ug/ $\mathrm{kg} / \mathrm{min} /$ period of time)

- Administration of inotropics (type and dose in $\mathrm{ug} / \mathrm{kg} /$ $\mathrm{min} /$ period of time $)$

- Lactatemia ( $\mathrm{mmol} / \mathrm{L} /$ period of time)

- Urine output ( $\mathrm{mL} /$ period of time)

- MAP (mmHg in the monitored time)

- CVP ( $\mathrm{mmHg}$ in the monitored time)

- $\mathrm{ScvO}_{2}$ or $\mathrm{SvO}_{2}$ (\% in the monitored time)

- Time of hemoculture taking (interval from the identification of severe sepsis/septic shock)

- Time of antibiotics administration (interval from the identification of severe sepsis/septic shock)

- Time of discharge from EPOSS-ICU (interval from the identification of severe sepsis/septic shock)

- Time of discharge from the hospital (interval from the identification of severe sepsis/septic shock)

- Time of death (interval from the identification of severe sepsis/septic shock) 